\title{
History of lower Pine Island Glacier, West Antarctica, from Landsat imagery
}

\author{
RoBert A. BINDSCHADLER \\ Laboratory for Hydrospheric Processes, Oceans and Ice Branch, NASA Goddard Space Flight Center, Code 971, Greenbelt, Maryland 20771, U.S.A. \\ E-mail: robert.a.bindschadler@nasa.gov
}

\begin{abstract}
A 28 year record of lower Pine Island Glacier, West Antarctica, constructed from 15 Landsat images, shows changes at the terminus, grounding zone and both margins. The north margin has expanded $5 \mathrm{~km}$ into the adjacent ice shelf in a sustained event that was underway in 1973 and may have begun in 1957. Between 1991 and 1997, this expansion ceased and a new region of rifting was created associated with an ice rise on the glacier's floating tongue. Changes in the topography of a nearby ice rise are used to deduce an upper-bound estimate of a $134 \mathrm{~m}$ thinning of the adjacent ice shelf. On the south margin, widening was limited to $1 \mathrm{~km}$ over the observation period and is seen propagating downstream in an intermediate-dated image. New areas of crevassing are also evident in the grounding zone of the glacier. Ice loss by the calving of large tabular bergs vastly exceeds mass loss by calving of many small bergs. These observations are consistent with reported changes of the 1990s and indicate that changes in the flow of Pine Island Glacier have occurred over the full period of satellite observations.
\end{abstract}

\section{INTRODUCTION}

Pine Island Glacier is one of the most active areas of the Antarctic ice sheet. Located at $75^{\circ} \mathrm{S}, 101^{\circ} \mathrm{W}$, it drains a major portion of the West Antarctic ice sheet into Pine Island Bay, an embayment of the Amundsen Sea. Not only does it discharge more ice than any other Antarctic outlet (Vaughan and others, 2001), but it is accelerating, its grounding line is retreating and its catchment area is thinning (Rignot, 1998; Wingham and others, 1998; Shepard and others, 2001). These observations of the glacier's speed and its grounding-line position were based on analyses of synthetic aperture radar (SAR) imagery collected from space during the 1990s. Thinning was deduced from radar altimeter data collected during the late 1980s and

Table 1. Images used in this study

\begin{tabular}{lcccccc}
\hline Date & $\begin{array}{c}\text { Sun } \\
\text { elevation }\end{array}$ & $\begin{array}{c}\text { Sun } \\
\text { azimuth }\end{array}$ & $\begin{array}{c}\text { Pixel } \\
\text { size }\end{array}$ & $\begin{array}{c}\text { Landsat } \\
\text { satellite No. }\end{array}$ & Path & Row \\
& $\circ$ & $\circ$ & $\mathrm{m}$ & & & \\
& & & & & & \\
\hline 24 January 1973 & 22.43 & 80.16 & 57 & 1 (MSS) & 246 & 114 \\
13 February 1975 & 16.95 & 79.40 & 57 & $2(\mathrm{MSS})$ & 249 & 113 \\
9 December 1981 & 26.45 & 79.18 & 57 & $3(\mathrm{MSS})$ & 247 & 114 \\
15 January 1982 & 24.73 & 80.28 & 57 & $3(\mathrm{MSS})$ & 248 & 113 \\
15 January 1982 & 23.69 & 83.03 & 57 & $3(\mathrm{MSS})$ & 248 & 114 \\
21 December 1986 & 28.47 & 74.66 & 28.5 & $5(\mathrm{TM})$ & 1 & 113 \\
18 December 1988 & 29.37 & 70.83 & 28.5 & $4(\mathrm{TM})$ & 1 & 113 \\
4 February 1989 & 21.05 & 73.90 & 28.5 & $4(\mathrm{TM})$ & 1 & 113 \\
19 November 1989 & 26.19 & 67.50 & 28.5 & $4(\mathrm{TM})$ & 1 & 113 \\
4 January 1990 & 24.63 & 73.24 & 28.5 & $4(\mathrm{TM})$ & 232 & 113 \\
20 February 1991 & 15.92 & 74.53 & 28.5 & $5(\mathrm{TM})$ & 232 & 113 \\
4 February 1997 & 19.96 & 77.88 & 28.5 & $5(\mathrm{TM})$ & 232 & 114 \\
4 February 1997 & 20.48 & 76.07 & 28.5 & $5(\mathrm{TM})$ & 232 & 113 \\
6 March 2000 & 12.08 & 65.27 & 28.5 & $7(\mathrm{ETM}+)$ & 1 & 113 \\
13 January 2001 & 27.56 & 69.60 & 28.5 & $7(\mathrm{ETM}+)$ & 233 & 113 \\
& & & & & & \\
\hline
\end{tabular}

the 1990s. These observations cannot be extended to earlier times because the data do not exist. Nevertheless, it is important to know if the observed behavior initiated recently or if it has been sustained over a longer period.

Field data are rare. No ground-based observations have been conducted since the last field party was on the glacier in the 1970s. Limited airborne radar soundings were collected in 1981 and 1998, but no observations of speed or precise elevation were made to compare with the satellite record. The longest record of the region exists in the form of optical imagery collected by the series of Landsat sensors. This data source provides an adequately dense and wholly unique dataset revealing changes that have occurred on Pine Island Glacier prior to 1973. This paper presents observations at the margins of the glacier widening, probably in response to thinning of the adjacent ice shelf, of more intense crevassing within the grounding zone, and a record of large calving events at the terminus.

\section{AVAILABLE IMAGERY}

The Landsat series of high-resolution imagers began in 1972 with the launch of the Earth Resources Technology Satellite (ERTS-1) and has maintained at least one imaging system in orbit ever since. Until the launch of Landsat 7, carrying the Enhanced Thematic Mapper Plus (ETM+) sensor, image requests were made by individual users. This limited the number of data collected. Other factors limiting the number of available Landsat data of Pine Island Glacier are the persistent cloud cover over the Antarctic coast, the long polar night and the frequent inability to collect Antarctic data. Often no suitable means to either record data on board or relay the data to a ground station existed when orbiting over Antarctica.

A complete search of the Landsat archive at the United 
States Geological Survey (USGS) Eros Data Center (EDC) yielded 19 multispectral scanner (MSS) images from Landsats 1-5, 27 Thematic Mapper (TM) images from Landsats 4 and 5, and 27 ETM+ images from Landsat 7. No other sources of Landsat data of this area, i.e. received at other ground stations, are known to exist.

A total of 15 images on 13 dates were selected for this study (Table 1). They span slightly less than 28 years, but are not spaced equally in time. The earliest scene was collected shortly after the initial Landsat launch. The longest time interval between useful scenes is approximately 6.8 years. In some cases, two consecutive scenes from a single orbit were required to obtain full glacier coverage.

Spatial resolution has steadily improved during the Landsat program. ERTS-1 data were collected at a raw pixel resolution of $57 \mathrm{~m} \times 79 \mathrm{~m}$. The early images used here were processed by EDC to a square pixel resolution of $57 \mathrm{~m}$ and corrected for known geometric distortions and radiometric offsets. Most recently, the ETM+ data included a $15 \mathrm{~m} \times 15 \mathrm{~m}$ panchromatic band, also corrected for known geometric distortions and radiometric offsets. For this study, band 4 (780-900 $\mathrm{nm}$ ) of each image was used at $57 \mathrm{~m}$ pixel resolution for the earlier data and $28.5 \mathrm{~m}$ pixel resolution for the later data.

\section{IMAGE CO-REGISTRATION}

The images were received in various projections. A geographic grid in the appropriate projection was applied to each image using the coordinates of the four corner points specified in the image metadata. The most recent image (13 January 2001) was chosen as the reference image based on the knowledge that the ETM+ has the least internal distortion of all the Landsat sensors. The projection of this image was Universal Transverse Mercator. Other images were fit to this base using a first-order warping with nearest-neighbor resampling to a $28.5 \mathrm{~m}$ pixel resolution. The co-registration was based solely on five common geographic coordinates used as tie points. Four of these tie points were distributed around the perimeter of the lower glacier, and one was on the lower glacier. ENVI software was used for all image manipulations.

Significant co-registration errors were noticed during the detailed examinations of specific regions. These errors were a few pixels for recent images (i.e. many tens of meters), but tens of pixels for older images (i.e. many hundreds of meters). It is not known whether this was the result of internal distortion in the original data, inaccuracies in the corner coordinates provided with the data, or the co-registration method described above. C. E. Rosanova (personal communication, 2001) reported less co-registration error when warping images based on common surface features and ignoring geographic information.

Co-registrations were refined further prior to the analysis of any local area. This additional co-registration was based on common surface features in the local area of interest. Rock outcrops were used where available, but in some cases snowcovered features in slow-moving areas were used. This stage of co-registration refinement was limited to linear offsets in the two orthogonal axes of the images. The offsets varied from one local region to another, but were usually less than ten pixels along either axis. Final misregistrations, estimated from flickering the images, were a few pixels locally (i.e. tens of meters for ETM+ images and generally $<100 \mathrm{~m}$ for MSS images).

\section{OBSERVED GHANGES}

\section{Overview}

This study focused on the lower portion of the grounded glacier and its floating tongue extending into Pine Island Bay (Fig. 1) because surface features are clearly discernible in this region. The area extends over roughly the final $100 \mathrm{~km}$ of the glacier, where it maintains a relatively constant width of $40 \mathrm{~km}$. The majority of the floating glacier is bounded by ice shelves on either side. The flow direction is generally east-to-west.

A variety of surface features populate the surface of the glacier. While it may be difficult to see these features in the lower resolution of Figure 1, they are more obvious in the detailed figures to follow.

Longitudinal flow stripes are topographic ridges and troughs indicating the general direction of motion. Dark bands in Figure 1 aligned with the flow stripes are areas of more exposed crevasses: shadows lead to the dark appearance (cf. Fig. 6). The crevasses are exposed due to the removal of surface snow by winds or snow-bridge collapse due to ice motion.

Flow stripes are most prominent on the floating tongue, but can be traced upstream onto the grounded glacier as well. Not all flow stripes are continuous. In a few cases, major flow stripes can be seen starting in mid-glacier, shifting laterally or curving. These situations are tied to isolated events in the flow history of the glacier, and, while they are worthy of further investigation, speculation as to specific causative events is not offered here.

Flow stripes are less obvious on grounded ice adjacent to the glacier, where the dominant topography is hummocky terrain dictated by the roughness of the underlying topography and the thickness of overlying ice. Hummocks disappear on the floating ice shelf where ice no longer must conform to underlying basal topography. Returning to the glacier's floating tongue, numerous crevasses are seen, primarily by the sagging of overlying snow bridges. These crevasses are also grouped into longitudinal avenues. In many cases, these avenues can be traced upstream to regions where the initial crevassing is observed. Where bridges collapse, an isolated hole is formed, usually accompanied by a tail of drifted snow oriented along the dominant wind direction.

Near the terminus of the glacier, many images show either an iceberg separated from the glacier or a large rift cleaved through the floating tongue, or both. These features represent the calving of the glacier that episodically releases icebergs into Pine Island Bay.

All of these surface features serve as markers that can be used to determine glacier motion and changes in flow between images. However, because of co-registration uncertainties, the analysis is based more on feature changes than displacements.

\section{North margin}

The ice north of the glacier is scattered with nunataks, ice rumples and ice rises, resulting in more precise image co-registration. The margin itself is clearly delineated by the difference between the smooth ice shelf and the crevassed and flow-stripe-rich glacier. The north margin also contains areas of very intense crevassing or rifting, suggesting the presence of local grounding.

A series of images of this area, shown in Figure 2, illustrates that the crevassing associated with this grounding 


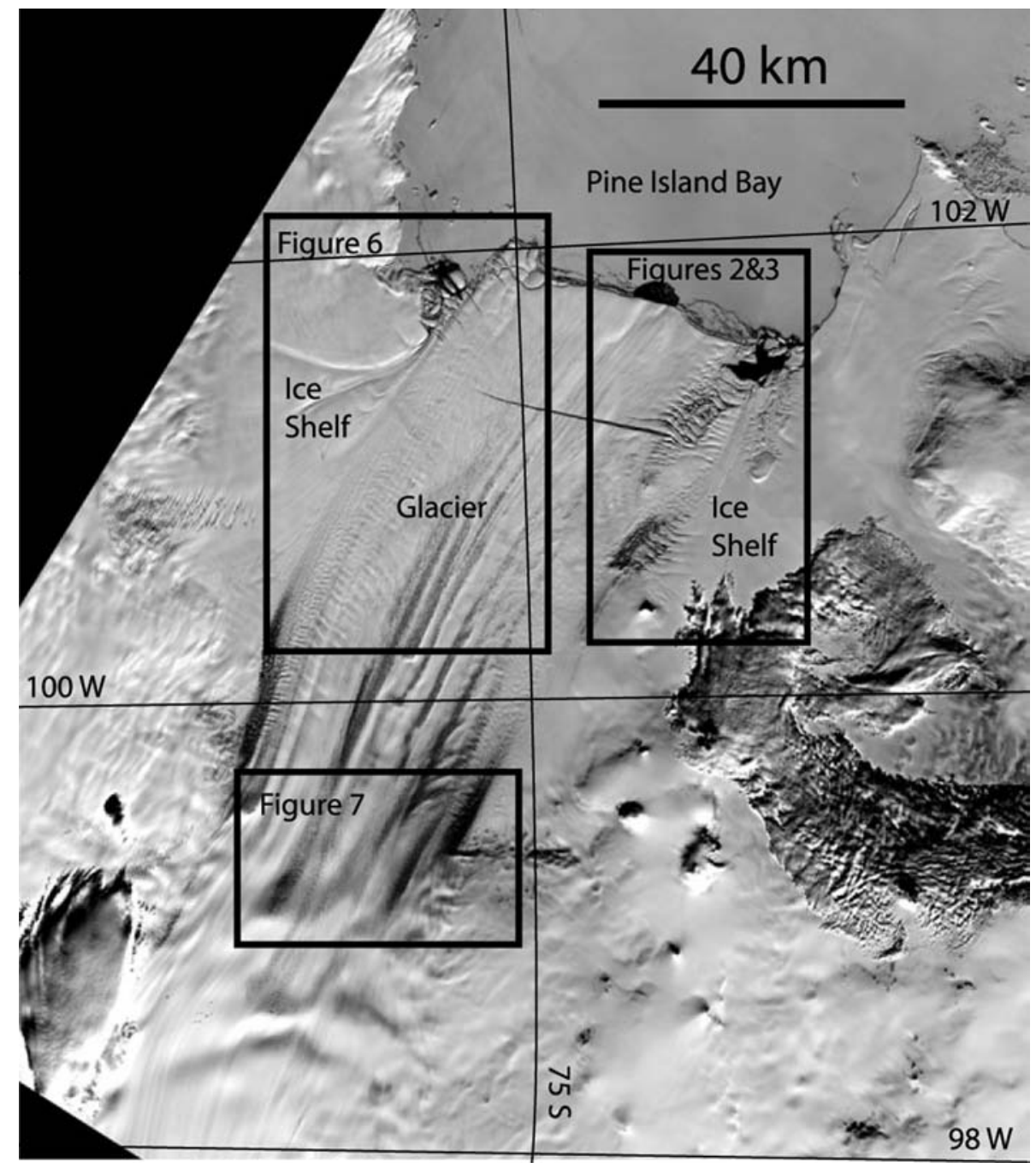

Fig. 1. A portion of the ETM+ image collected on 13 January 2001 showing lower Pine Island Glacier. The glacier flows from the lower left of the figure to the upper middle. Outlined boxes indicate the positions of subsequent figures.

was not as intense as in the past. One rifted area is associated with a nearly circular ice rise (labeled "a" in Fig. 2). Prior to the 1990 image, the rifting associated with this ice rise is limited to the south side of the rise. By the time of the 1997 image, the rifting has become more extensive and the location has migrated across stream so that it now occurs directly downstream of the surface expression of this rise. Similarly, there is a second area of rifting ("b" in Fig. 2) that is rather modest from 1973 to 1990. By 1997, however, this area's extent and the rifting intensity within it have greatly increased. Finally, there is a third feature ("c" in Fig. 2) that does not appear at all in the 1990 image or before.

More information about the change that appears to take place between 1990 and 1997 is gleaned from the position of the margin. Figure 3 shows the positions of this margin in each of the 10 images of the region. The margin migrated laterally from 1973 until 1991. Over this 18 year period it shifted steadily $2.5 \mathrm{~km}$ northward into the adjacent ice shelf at an average rate of $140 \mathrm{~m} \mathrm{a}^{-1}$. Assuming the margin was straight before the bulge began to form and the lateral migration rate was constant, the migration is estimated to have begun 16 years earlier, in 1957.

Between 1991 and 1997 a major change occurred in the margin's evolution. After the 1991 image, it migrated no further into the ice shelf. However, the position of the maximum excursion of the bulge appears to have accelerated as it moved downstream. From 1982 to 1991, the average downstream motion was $565 \pm 50 \mathrm{ma}^{-1}$. Between 1997 and 2001, this rate nearly trebled to $1550 \pm 500 \mathrm{~m} \mathrm{a}^{-1}$, but with a greater uncertainty due to the lengthening of the bulge. Interferometric radar measurements of the year 2000 velocity field in this area are approximately $600 \mathrm{~m} \mathrm{a}^{-1}$, with no suggestion of longitudinal acceleration (personal communication from E. Rignot, 2001). Thus, the bulge probably propagated as a kinematic wave along the glacier margin.

Despite the lack of continuous observations, it is highly probable that the change in rifting and the change in the margin's lateral excursion are related to a common change in the stress state in this region of the glacier. A discussion of possible causes is taken up in a later section.

\section{Ice-shelf thinning}

There is an ice rise with a prominent, bright sickle-shaped upstream boundary just north of the northern glacier margin (cf. Fig. 2 and the right edge of Fig. 3). This boundary appears bright because it is inclined toward the sun. This sun-inclined slope lengthens through the image record. The slope length in each image was measured by counting the number of pixels brighter than the surrounding ice shelf along a line nearly parallel to the sun's azimuth for that image. Uncertainty in defining the ends of the slope is largest in the older imagery where both the original pixel size and image noise are larger than in more recent imagery. Uncertainty values $(3 \sigma)$ are estimated as $\pm 114 \mathrm{~m}$ (two $57 \mathrm{~m}$ pixels) in the earliest imagery and $\pm 57 \mathrm{~m}$ (two $28.5 \mathrm{~m}$ pixels) in the later imagery. 


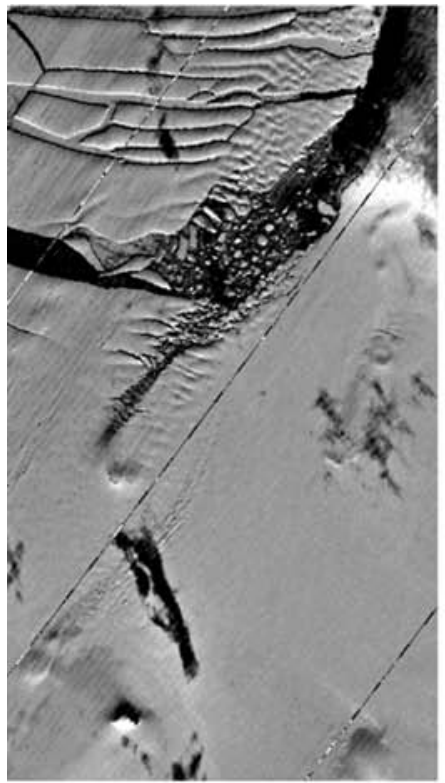

January 24,1973

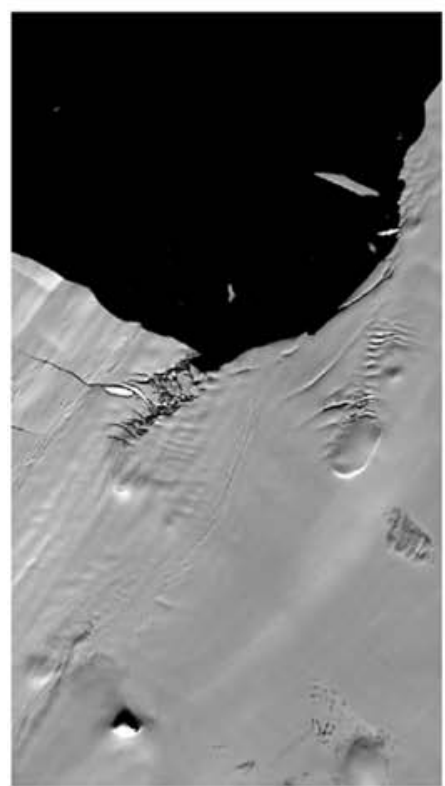

January 4, 1990

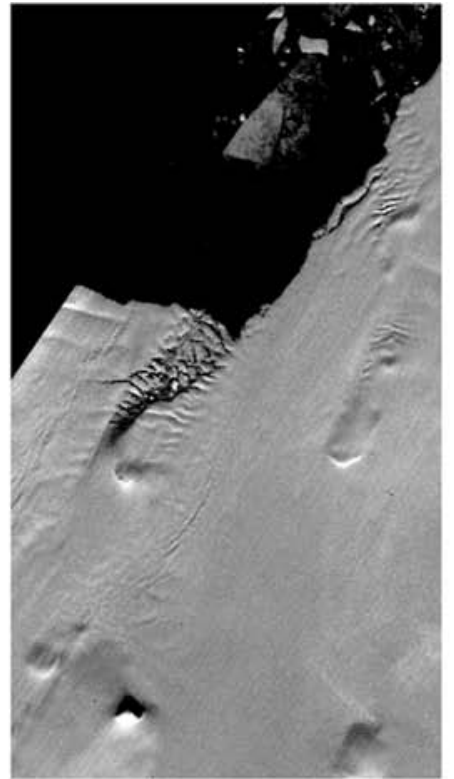

January 15,1982

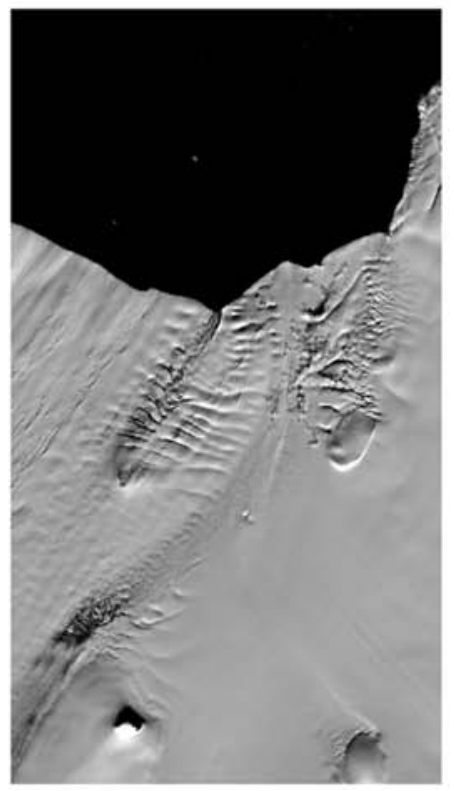

February 24,1997

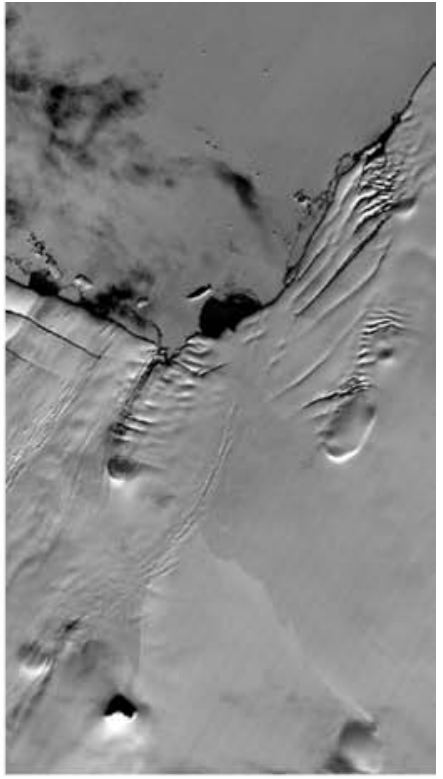

December 21, 1986

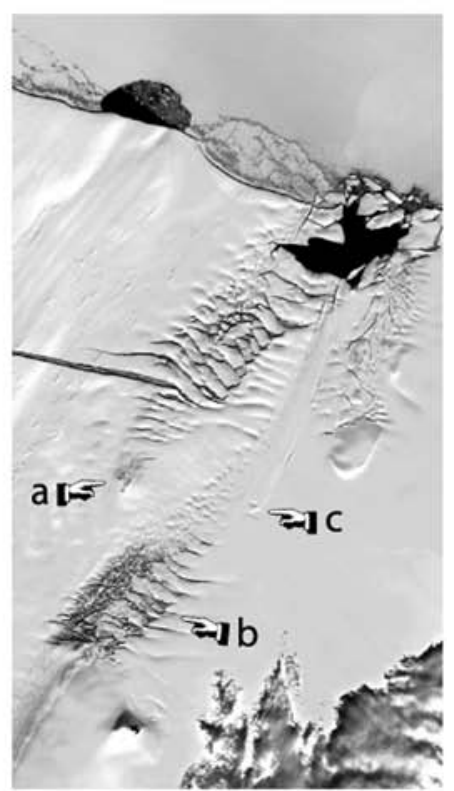

January 13, 2001

Fig. 2. Six sub-images of the north margin region of Pine Island Glacier collected on the dates indicated. Features " $a$ " " $b$ " and "c", identified in the latest image (lower right), are discussed in the text.

A smaller, additional uncertainty arises from the variation in solar elevation and azimuth (see Table 1). The measurements shown in Figure 4 indicate that the length of the slope has nearly doubled over the 28 years, from $450 \mathrm{~m}$ to $840 \mathrm{~m}$.

The topography of the ice rise is calculated by applying the photoclinometric equation (Bindschadler and Vornberger, 1994):

$$
\mathrm{DN}=C\left[I R \cos (\theta-\alpha)-L_{0}+S\right]
$$

and

$$
C=\frac{255-0}{L_{\mathrm{s}}-L_{0}},
$$

where DN is the image brightness, $C$ is the conversion of radiance to image brightness (in DN units), $I$ is the exo- atmospheric irradiance, $R$ is reflectance of the surface, $\theta$ is the solar zenith angle, $\alpha$ is the component of surface slope in the direction of the sun, $L_{0}$ and $L_{\mathrm{s}}$ are the radiance offsets at $\mathrm{DN}=0$ and $\mathrm{DN}=255$, respectively, and $S$ is the irradiance from atmospheric scattering. Data were used from the $13 \mathrm{Janu}-$ ary $2001 \mathrm{ETM}+$ image because it has the best sensor calibration. For ETM,$+ L_{0}$ and $L_{\mathrm{s}}$ are -5.1 and $157.4 \mathrm{~W} \mathrm{~m}^{-2} \mu \mathrm{m}^{-1}$, respectively, and $I$ is $347 \mathrm{~W} \mathrm{~m}^{-2} \mu \mathrm{m}^{-1}$ in the ETM+ band 4 used here.

Assuming the mean slope on the ice shelf in front of the ice rise is flat $(\alpha=0)$, the average $\mathrm{DN}$ for that area can be used to remove $S$ from Equation (1). Using the average value of DN $=196$ for the ice shelf near the ice rise, and recalling from Table 1 that $\theta=62.44^{\circ}$, results in $S=0$ when $R=0.81$. This reflectance value is consistent with measurements of spectral 


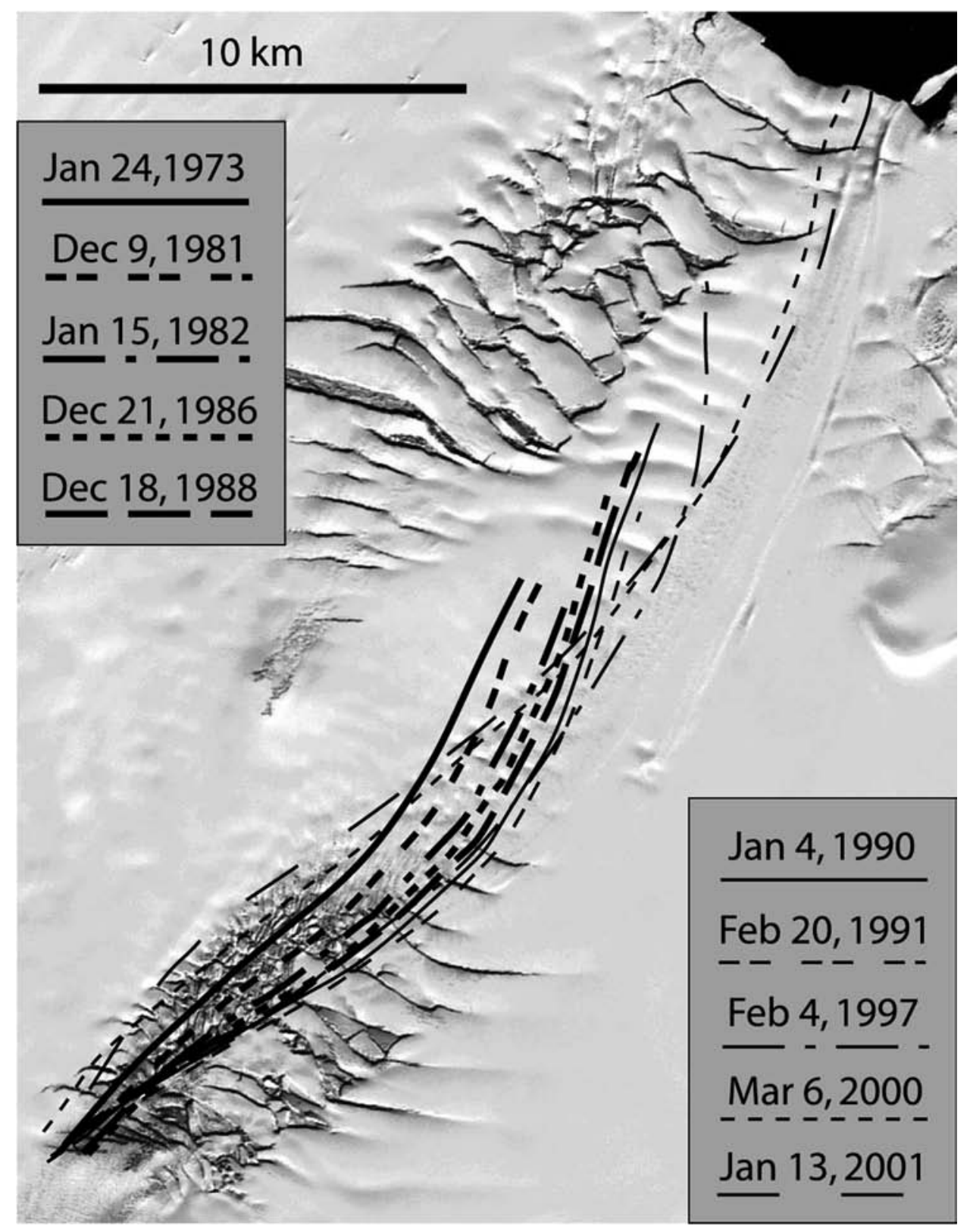

Fig. 3. Close-up of 13 January 2001 ETM+ image of the north margin of lower Pine Island Glacier. Margin positions traced from other images are superimposed in different line weights and patterns.

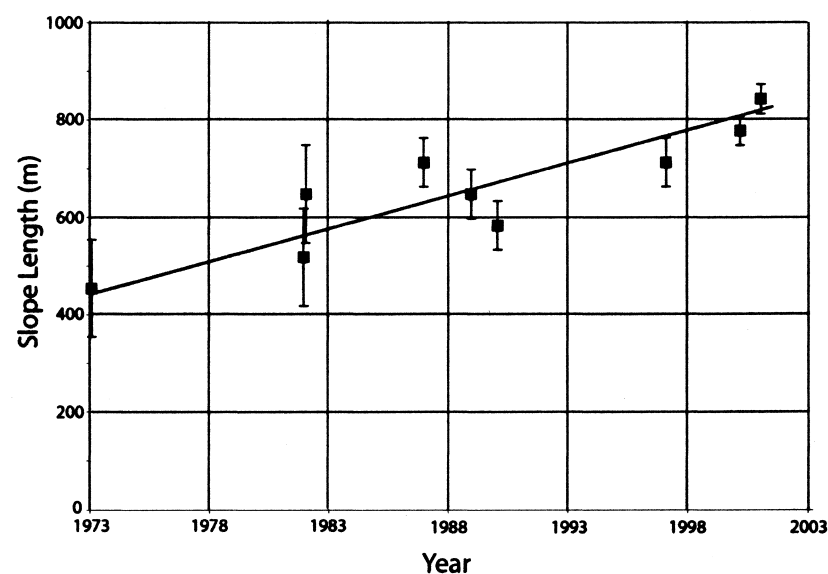

Fig. 4. Length of the sun-inclined slope of the ice rise discussed in the text.

reflectance of large-grain alpine snow cover (Dozier, 1989). Although $S$ is probably not exactly zero, it is usually small (a few DN) for polar conditions where atmospheric aerosols and water-vapor content are low. A value for $S$ of $5 \mathrm{DN}$ changes the spectral reflectance to 0.79 .
To convert a transect of pixel brightnesses to slope values, the transect must be oriented parallel to the solar illumination direction. For this image, a $20^{\circ}$ rotation was required. The resulting elevation profile derived from the integration of slopes calculated from Equation (1) placed the ice-rise summit $28.8 \mathrm{~m}$ above the ice shelf. For the case of $R=0.79$ (and $S=5 \mathrm{DN})$, the summit is $<1 \mathrm{~m}$ higher.

The change in the length of the slope (Fig. 4) can be used to estimate the thinning that might have occurred from 1973 to 2001. Assuming the mean slope was fixed during this period at 0.034 (28.8 $\mathrm{m}$ elevation over $840 \mathrm{~m}$ distance), the $450 \mathrm{~m}$ slope in 1973 represents an ice-rise summit only $15.4 \mathrm{~m}$ above the ice shelf. If the summit stayed at a constant elevation, the shelf surface elevation dropped $13.4 \mathrm{~m}$. Assuming the loss was entirely ice at a density of 0.9 implies a reduction in ice-shelf thickness of $134 \mathrm{~m}$. Averaged over 28 years, this thinning produces an average rate of $4.8 \mathrm{~m} \mathrm{a}^{-1}$. Although this is in addition to the steady-state melt rate, it is within the large subglacial melting rates estimated for Pine Island Glacier (Rignot, 1998). It is possible that if the thinning is rapid, the mean slope has decreased over time as the flank of the ice rise extends farther onto the former floating 


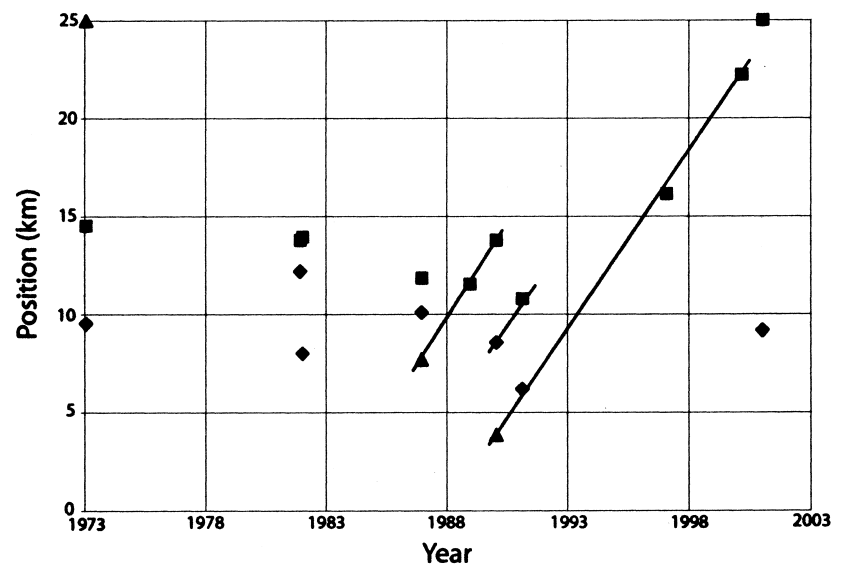

Fig. 5. Rift and terminus positions measured along a longitudinal axis of flow near the north margin of Pine Island Glacier. Squares represent the terminus, diamonds the first major rift upstream and triangles the second major rift upstream. The parallel lines indicate a motion of the rifts and terminus at $1700 \mathrm{ma}^{-1}$.

ice shelf. In this case, the earlier summit would have been higher than calculated here, and the ice-shelf thinning less. If some of the thinning removed air in the firn, the thinning would also be somewhat less. Without an accurate means to calculate this effect, it is best to view the $134 \mathrm{~m}$ estimate of thinning as an upper bound.

\section{Calving}

An obvious occurrence in the image sequence of Figure 2 is the release of large tabular icebergs and the resultant jumps in terminus position. Icebergs form when a single rift propagates the entire width of the glacier. Figure 5 plots the position of the ice front and the upstream edge of long rifts (when present) in each image along a longitudinal line approximately $12 \mathrm{~km}$ south of the north margin (near the edge of the images in Figure 2).

Figure 5 bears out the expected connection between a rift that advects steadily toward the front and the terminus location after a calving event. The velocity of $1700 \mathrm{~m} \mathrm{a}^{-1}$ derived from the slope of the three lines in Figure 5 is less than the center-line speed of Pine Island Glacier because the measurements were taken nearer the north margin where the long rifts first appear. The routine formation of long rifts only on the north margin may relate to the formation process itself. The smooth connection between rift position and later terminus position implies that Pine Island Glacier calves predominantly large icebergs.

The image record is not temporally dense enough to follow the details of terminus position. Calving must have occurred whenever the terminus moves upstream, but it also must have occurred when the later terminus position falls below the projected position of the rift farthest downstream, as between 1991 and 1997. No fewer than five calvings must have taken place over the 28 year record.

The 1973 image shows a large iceberg adjacent to the glacier. The proximity of the iceberg, and the observation of rapid offshore removal of icebergs subsequent to other calving events, suggests the calving occurred just prior to the 1973 image date. If so, the terminus was well extended at the beginning and end of this 28 year interval, but consistently 9-14 km farther upstream during the period in between.
There is no way to know with a short dataset if this is a periodic behavior. It is left here for future explanation.

\section{South margin}

Pine Island Glacier also changed along its south margin. Figure 6 shows the shifts in prominent longitudinal features. On the glacier, the margin shifted laterally $1 \mathrm{~km}$ near its downstream end from 1973 to 2001. Forty kilometers upstream, there was no perceptible shift in margin position. The margin in the 1986 image captures the southward shift $20 \mathrm{~km}$ downglacier of where the 1973 and 2001 margins diverge. Thus, this change traveled down-glacier at an average rate of $1400 \pm 100 \mathrm{~m} \mathrm{a}^{-1}$, a reasonable velocity for close to the margin of a glacier with a center-line speed in excess of $2.2 \mathrm{~km} \mathrm{a}^{-1}$.

A flow stripe parallel to the margin and on the glacier was displaced almost identically to the margin, suggesting the widening occurred nearer the center of the glacier. The ice between this flow stripe and the margin enters the glacier from a southerly tributary just below the grounding line (cf. Fig. 1). The ice north of this flow stripe forms the main trunk of the glacier that discharges the interior ice sheet. The southward push of this margin seems to have originated from changes in the main glacier and not the tributary that joins downstream of the grounding line.

There are also changes in the ice shelf adjacent to the glacier. The prominent trough closest to the glacier also moved southward by an amount similar to the margin shift, but the next trough did not. The second trough appears to be fixed by an elevated region of very smooth ice, around which the ice exiting through Pine Island Glacier must flow.

\section{Grounding zone}

At the grounding zone of the glacier, numerous strips of crevasses first appear. Many of these are visible on the full set of images. Figure 7 compares the 1973 and 2001 images within the region that includes the grounding zone extending to the north edge of the glacier. The improvement in image quality and spatial resolution is apparent, and most of the features appear in both images. On the left of the figure, various sets of crevasses appear wider in the 2001 image than in the 1973 image. This may be due to the particular snow conditions, and any significant difference in dynamic conditions of the glacier at these two times is questionable.

Significant differences between these two images appear in the right half of Figure 7. Within the oval drawn on the 2001 image, there are areas of intense crevassing in 2001 that are devoid of crevasses in 1973. This suggests that the shearing at this side of the glacier increased from 1973 to 2001. In addition, the ogive-like waves in the 1973 image have been noticeably altered in the 2001 image.

\section{DISGUSSION}

It is tempting to relate the margin migrations on both sides of Pine Island Glacier to thinning of the adjacent ice shelf. Satellite radar altimetry records elevation decreases extending all along the Amundsen Sea coast, indicating substantial thinning of the floating ice (personal communication from H. J. Zwally and others, 2002). A direct inference of substantial thinning is afforded by the observations of the ice rise near the north margin.

Although no ice thicknesses are known in this local area, 


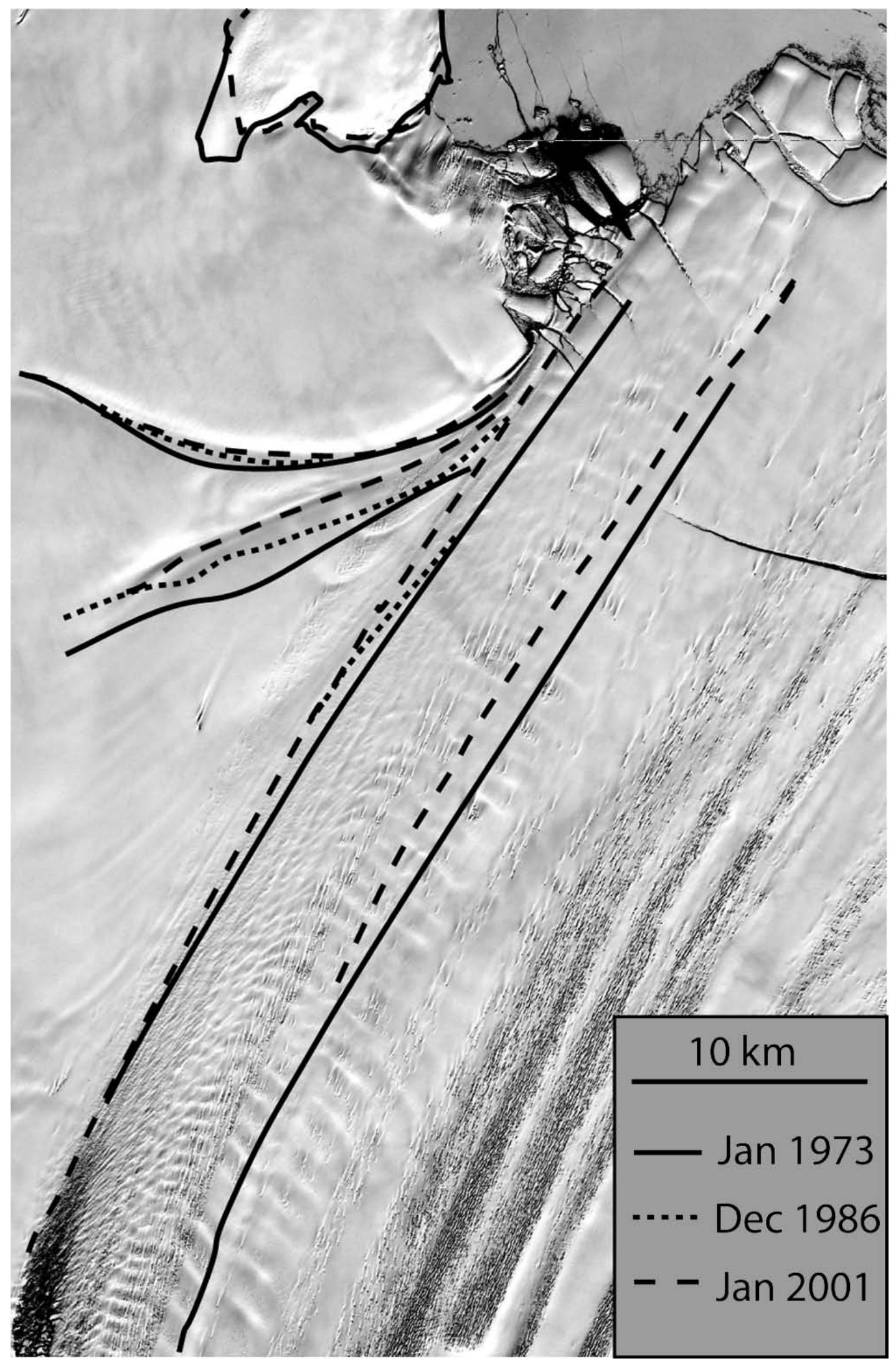

Fig. 6. Close-up of 13 January 2001 ETM + image of the south margin of lower Pine Island Glacier. Margin and prominent flowstripe locations for the 24 January 1973 and 21 December 1986 images are superimposed to show migration widening of the glacier over this time period.

there are some nearby data that are useful. Airborne radar soundings along a longitudinal line down Pine Island Glacier were flown in 1981 (Crabtree and Doake, 1982). The thickness approximately $25 \mathrm{~km}$ upstream of the terminus was $550 \mathrm{~m}$. However, a large transverse gradient was also measured farther upstream. In 2001, Bindschadler and Rignot (2001) calculated a cliff height of $87 \mathrm{~m}$ from the shadow length of the large rift seen in the 13 January 2001 image. These observations are used to estimate the ice thickness of the glacier in the vicinity of this area is $700-900 \mathrm{~m}$. It is doubtful that the ice shelf is thicker than this.

Considering the margin migrations on both sides of the glacier, the total widening from 1973 to 2001 was $3.5 \mathrm{~km}$. Over a $36 \mathrm{~km}$ width, the average strain is $9.7 \%$ and the 


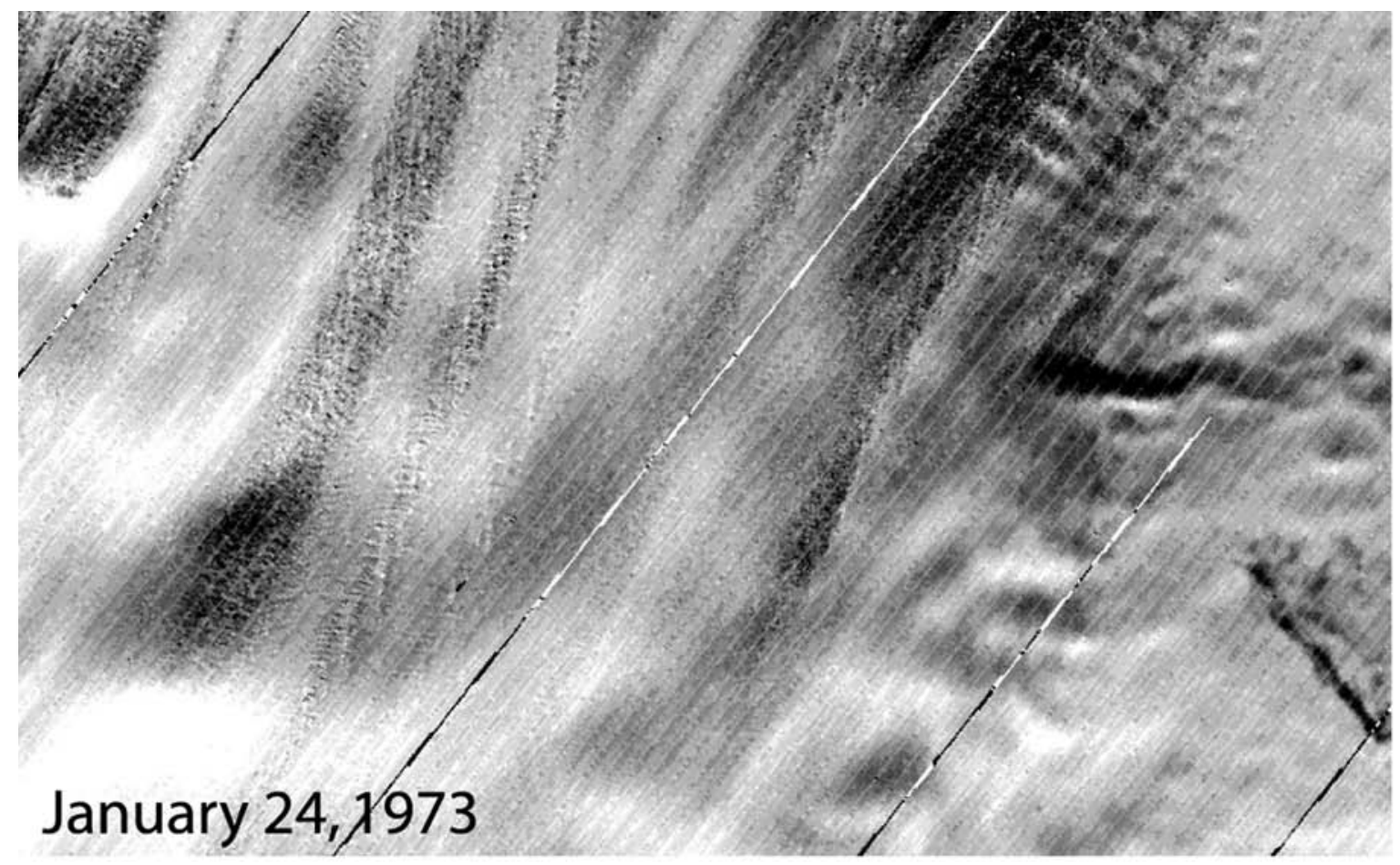

\section{$20 \mathrm{~km}$}

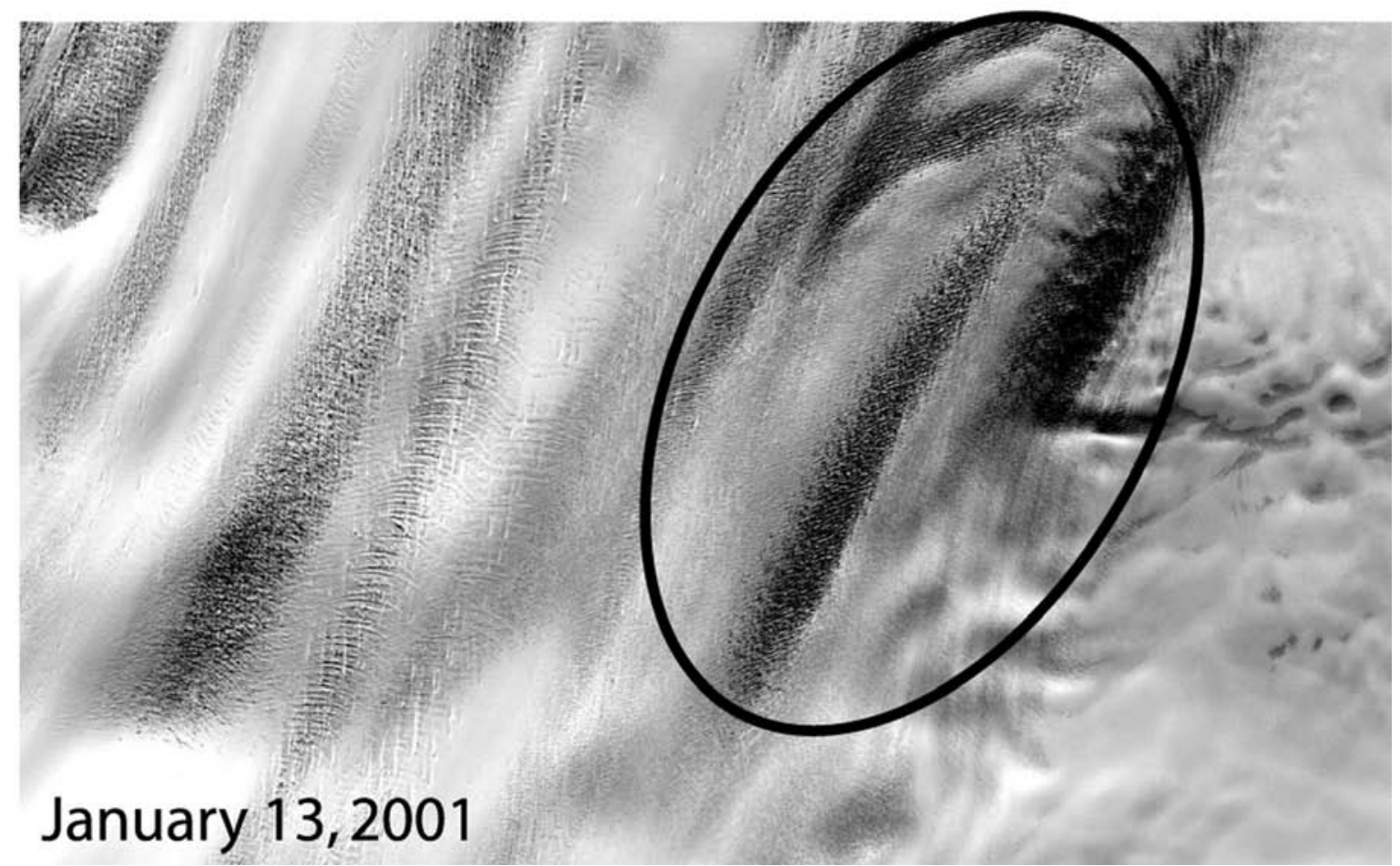

Fig. 7. Grounding zone of Pine Island Glacier on 24 January 1973 (upper panel) and 13 January 2001 (lower panel). Outlined oval includes areas of new crevassing.

strain rate is $0.0035 \mathrm{a}^{-1}$. Applying this strain to the vertical, the glacier should thin by $68-87 \mathrm{~m}$ if the glacier maintained the same flux into this cross-section. This range is less than the $134 \mathrm{~m}$ thinning calculated for the northern ice shelf; however, recall that the $134 \mathrm{~m}$ figure was an upper bound and that observations of both the north and south margins illustrated that the lateral strain was not uniform. There may not be a significant disagreement, avoiding the need to infer any residual hydrostatic imbalance.

The sudden changes between 1991 and 1997 (rifting in region "b" (Fig. 2) and cessation of migration of the north margin) are also intriguing in light of other observations reported by Rignot (1998). He produced SAR interferograms that showed the position of the hinge line (similar to the grounding line) retreated from 1992 to 1996 . While he chose to view the retreat as gradual, at an average rate of $1.2 \mathrm{~km} \mathrm{a}^{-1}$, his data also support the interpretation that the hinge line retreated suddenly between early 1992 and early 1994. A distance of $>40 \mathrm{~km}$ separated the two changing areas reported here, but there may be a connection. It is possible that the ability of ice to flow completely around the circular ice rise labeled "a" in Figure 2 caused a transfer of stress within this 
region so that stress was transferred upstream to the ice rise labeled "b" and its subsequent rifting. Modeling is underway to address these hypotheses.

The rifting caused by the ice rise labeled "a" creates the large rifts that eventually form all the icebergs observed in the image record. The shape of this rifted area changes between 1991 and 1997 once the bulge in the margin moves past the ice rise. The interferometric radar map of surface velocity (personal communication from E. Rignot, 2001) confirms that in 2000 the ice in this bulge is flowing rapidly and the glacier is quickly moving past this ice rise on both sides.

\section{SUMMARY}

The record of Landsat images extends the record of Pine Island Glacier observations backward to 1973. Despite the intermittent nature of the sequence, the dataset shows that measurable changes have occurred over a 28 year observation period. Most notably, the north margin has migrated into an ice shelf that is thinning at an average rate possibly as large as $4.8 \mathrm{~m} \mathrm{a}^{-1}$. The nature of this migration shows an initial expansion, during which the ice begins to flow around an ice rise within the glacier. Between 1991 and 1997 the lateral migration of the margin ceases, and a new area of rifting, along with a new ice rise, appears closer to the migrated margin.

The ability to quantify ice-shelf thinning shows the power of temporal series of high-resolution imagery. While the calculations deserve validation, the procedure shows how unique glaciological situations can be studied in the absence of field observations.

The image record also documents widening along the downstream end of the south margin of the glacier and new crevassing within the grounding zone, where the floating tongue begins. There may be a connection between all these changes, as well as with other observations of change on the glacier, but this must await a sound dynamic modeling study.

\section{AGKNOWLEDGEMENTS}

C. E. Rosanova provided the 13 January 2001 image. E. Rignot provided useful insight into the evolving analysis. G. S. Hamilton, N.W. Young and T. A. Scambos (Scientific Editor) provided thorough reviews that substantially improved this report. The work was performed with support received from NASA's Earth Science Enterprise and the U.S. National Science Foundation's Office of Polar Programs.

\section{REFERENGES}

Bindschadler, R. A. and E. Rignot. 2001. Crack! In the polar night. Eos, $82(43), 497,505$

Bindschadler, R. A. and P. L. Vornberger. 1994. Detailed elevation map of Ice Stream C, Antarctica, using satellite imagery and airborne radar. Ann. Glaciol., 20, 327-335.

Crabtree, R. D. and C. S. M. Doake. 1982. Pine Island Glacier and its drainage basin: results from radio-echo sounding. Ann. Glaciol., 3, 65-70.

Dozier, J. 1989. Spectral signature of alpine snow cover from the Landsat Thematic Mapper. Remote Sensing Environ., 28, 9-22.

Rignot, E.J. 1998. Fast recession of a West Antarctic glacier. Science, 281 (5376), 549-551.

Shepherd, A., D. J. Wingham, J. A. D. Mansley and H. F. J. Corr. 2001. Inland thinning of Pine Island Glacier, West Antarctica. Science, 291 (5505), 862-864.

Vaughan, D. G. and 9 others. 2001. A review of Pine Island Glacier basin, West Antarctica: hypotheses of instability vs. observations of change. In Alley, R. B. and R. A. Bindschadler, eds. The West Antarctic ice sheet: behavior and environment. Washington, DC, American Geophysical Union, 237-256. (Antarctic Research Series 77.)

Wingham, D. J., A. L. Ridout, R. Scharroo, R. J. Arthern and C. K. Shum. 1998. Antarctic elevation change 1992 to 1996. Science, 282(5388), 456-458.

Zwally, H. J. and 15 others. 2002. ICESat's laser measurements of polar ice, atmosphere, ocean and land. f. Geodyn., 34, 405-445. 